\title{
INTERFERENCE MEASUREMENTS IN THE SPECTRA OF ARGON, KRYPTON, AND XENON
}

\author{
By W. F. Meggers
}

ABSTRACT

The spectra of the inert gases, especially of the heavier ones, contain strong lines which represent wave lengths possessing a high degree of homogeneity and reproducibility and these lines are therefore suitable for use as standards of wave length. This paper gives the values of 50 wave lengths in the spectrum of argon ( 3948 to 852 I A), 18 of krypton ( 4273 to $7601 \mathrm{~A}$ ), and 12 of xenon ( 4500 to $4923 \mathrm{~A}$ ), all of which have been compared with the wave length of the red radiation from cadmium $(6438.4696 \mathrm{~A})$ which is the international primary standard. These wave-length comparisons were made by means of etalon interferometers and most of the values are probably correct to one part in several millions. The elegance and precision of the interferometer methods for wave-length comparisons are demonstrated by the close agreement between values obtained by different observers, and also by the constant frequency differences of many of the lines belonging to combination series. There are only a few cases where independent observers differ by $0.004 \mathrm{~A}$ or more. From the wavelength measurements in argon and krypton, frequency differences are obtained which are constant within the probable error of the measurements. This further confirms the exactness of the Combination Principle of Ritz. If these frequency differences are regarded as true constants, they testify to the accuracy in relative value of the wave-lengths involved.

\section{CONTENTS}

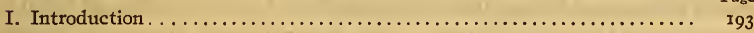

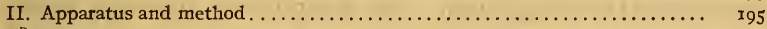

III. Results. . . . . . . . . . .

IV. Summary $\ldots \ldots \ldots \ldots \ldots \ldots \ldots \ldots \ldots \ldots \ldots \ldots \ldots \ldots \ldots \ldots, 202$

\section{INTRODUCTION}

interferometer comparisons of wave lengths with the object of establishing satisfactory secondary standards were undertaken by this Bureau some years ago and have resulted in the following publications in this Bulletin:

I. "Wave lengths of neon," 1 in which the wave length of the neon line $5852 \mathrm{~A}$ is compared with the cadmium standard and values for nine other neon lines are obtained relative to $5852 \mathrm{~A}$.

2. Interference measurements of "Wave lengths in the iron spectrum,"' giving the values for $\mathrm{I} 25$ iron lines (285 I to 37 or $\mathrm{A}$ ) 
as suitable standards derived from the international primary standard.

3. "Interference measurements of wave lengths in the iron spectrum," 3 where 402 wave-length values (3701 to $6750 \mathrm{~A}$ ) are given, most of which are tertiary standards interpolated between the accepted international secondary standards by the Buisson and Fabry interferometer method.

4. "Wave lengths of the stronger lines in the helium spectrum," "presenting $2 \mathrm{I}$ values (2945 to $728 \mathrm{I} \mathrm{A}$ ).

5. "Measurements of wave lengths in the spectrum of neon." 5 The wave lengths of 55 lines lying in the region 3369 to $8495 \mathrm{~A}$ are given in this paper.

Further work of this kind has recently Deen resumed in the spectroscopic laboratory of this Bureau and values obtained for the stronger lines in the spectra of argon, krypton, and xenon are presented in this paper.

The importance of accurate measurements of wave lengths in the spectra of the inert gases can scarcely be overestimated. It was shown by Buisson and Fabry ${ }^{\circ}$ that spectrum tubes of these gases, especially the heavier ones, give lines which possess a high degree of homogeneity: In fact, they are the narrowest spectral regions of emission which are known at the present time. The wave lengths are therefore susceptible of very precise measurement, and this precision together with reproducibility and convenience in operating the source are considerations which recommend the use of these lines as standards of wave length, or even as fundamental units of length. For several years the wave lengths of helium and neon lines have been in continuous use at this Bureau for the accurate length measurements of precision end standards and gage blocks, and for a study of the doubtful permanency of such material standards. ${ }^{7}$

In addition to their practical value as units of length or standards of wave length, emission lines in the spectra of the inert gases, because of the precision with which they can be measured, are of great theoretical interest in unravelling the laws of spectral series, calculation of fundamental spectroscopic constants, etc.

In the case of each of the gases-neon, argon, krypton, and xenon-frequency differences which were suspected of being constant had long been observed but it remained for the interier-

${ }^{3}$ B. S. Bull., 13, p. 245; 1916.

1 B. S. Bull., 14, p. 159; 1917.

- J. de Phys. (5), 2, p. 442; xgr2.

B. S. Bull, 14, p. 765 ; 1918 .

7 Peters and Boyd, Am. Machinist, Sept. 30 and Oct. 7, $x 920$. 
ometer comparisons, first made in the case of neon, to prove that these frequency differences are really constant to the limit of accuracy obtainable in wave-length measurements at the present time. This was a complete confirmation of the Combination Principle of Ritz and gives some conception of the extreme nicety with which the atom is constructed. It will be shown below that frequency differences in the spectra of argon and krypton are also constant to the same degree as in neon. It should also be mentioned that these constant differences in the spectra of the inert gases which have attracted attention for many years have only recently disclosed their physical significance and hence assumed considerable theoretical value. The constant differences in neon, for example, have very recently been arranged into spectral series by Meissner ${ }^{8}$ and more completely by Paschen. ${ }^{\circ}$ Thus the spectrum of neon which had puzzled spectroscopists for a long time has suddenly become one of the most completely and accurately defined sets of series, comprising over 800 lines between the wavelength limits 256I and 9314 A. More extensive wave-length measurements are required before the spectra of argon, krypton, and xenon can be discussed in a similarly complete and final manner. Whereas in the case of neon, the greatest number of related convergence limits was found to be ro, the maximum number of related subordinate series limits in argon, according to Nissen, ${ }^{10}$ is $\mathrm{I}$. In the helium spectrum a series system of doublets is known. It may therefore be expected that in the remaining rare gases, krypton and xenon, the number of related subordinate series limits will be found equal to the number of electrons in the atom; that is, 36 to 54 , respectively.

\section{APPARATUS AND METHOD}

The apparatus consisted of spectrum tubes, Fabry and Perot etalon-type interferometers, spectrographs, and a measuring engine. The general method of making wave-length comparisons with such equipment was originated by Fabry and Perot. ${ }^{11}$ It is the approved method by which the international secondary standards have been obtained and has been described so often ${ }^{12}$ that it is unnecessary to repeat its description here.

8 Ann. d. Phys., 58, p. 333; 1919.

Ann. d. Phys., 60, p. 405 ; 19 rg.

10 Phys. Zs., 21, p. 25; 1920.

II Ann. d. Chim., 25, p. x10; 1902.

12 Lord Rayleigh, Phil. Mag. (6), 11, p. 685; 1906. Eversheim, Ann. d. Phys., 30, p. 815; 1909. Fabry and Buisson, Astroph. J., 28, p. 169; rgo8. Pfund, Astrophys. J., 28, p. 297 ; 1908. 
Tubes containing either cadmium vapor or one of the inert gases (neon, argon, krypton, xenon) were made luminous by a high potential alternating current of 10 to 30 milliamperes. All the tubes were made with internal electrodes of aluminum. Light was taken from the central portion $(5 \mathrm{~mm}$.) of tube capillaries except in the case of cadmium, which was used "end on." The neon, argon, and cadmium tubes were made at this Bureau but tubes of krypton and xenon were imported, it being impossible to obtain in America sufficient quantities of these gases in a pure state. One quartz tube each of krypton and xenon was filled a number of years ago by the late Sir William Ramsey, and several small glass tubes containing krypton and xenon were recently obtained from Geissler Nachfolger.

All the rare gases, especially the heavier ones, cause sputtering of the electrodes on the walls of the tubes. It appears that this electrode deposition imprisons some of the gas so that ultimately the tubes become vacuous and resist the passage of any current. This phenomenon has been described by Collie, ${ }^{13}$ who states that heating the tube recovered part of the gas in the case of krypton, but had little effect on xenon. Collie tried xenon tubes with cathodes of platinum, aluminum, or copper and found that "with copper, although a very large amount of the cathode is volatilized, the disappearance of the xenon proceeds more slowly." It may be that some other metal which has even less effect than copper could be found.

The electrode deposit occurs very rapidly when the gas pressure in the tube is very low. Such was the case with the Geissler tubes which, though filled with pure gas, were at such low pressure that the cathode dark space reached the walls of the tube and cathode ray bombardment caused the well-known green fluorescence in the glass. These tubes deposited the electrode material on the walls with such speed that a 5 to 30 minute run put bright mirrors on the bulbs, the tubes thereafter becoming vacuous and worthless.

It is also observed that with increasing deposit and consequent decreasing gas pressure the tubes have a tendency to emit the so-called second spectrum instead of the first. At a certain stage near the end of the life of the tube a flickering color change takes place in the capillary and examination with a direct-vision spectroscope shows that the first and second spectra are emitted

${ }^{12}$ Proc. Roy. Soc., 97, p. 349; 1920. 
either together or alternately. These facts are mentioned as .more or less objectionable features in the use of rare gas tubes as sources of standard wave lengths. Tubes filled in our laboratory with helium, neon, and argon to pressures corresponding to several millimeters of mercury have been operated for several hundred hours without becoming vacuous and it seems probable that tubes of krypton and xenon would be relatively permanent if filled in the same way. It is worth while to experiment further to discover the specifications as to gas pressure, electrode material, current strength and potential, etc., which will increase the life and usefulness of spectrum tubes of the heavier inert gases.

A spectrograph with rock-salt prism and quartz lenses, designed especially for work in the ultra-violet spectrum, was used to record the interference rings for lines between 3300 and $7600 \mathrm{~A}$ on plates stained with pinacyanol. The spectrum of argon was further investigated from 6000 to $8500 \mathrm{~A}$ by means of interferometers used with a concave grating mounted in parallel light. Plates stained with dicyanin were used for these longer waves. The exposures with the prism spectrograph ranged from 30 to 60 minutes each for the rare gas spectra and I or 2 minutes for the cadmium spectrum. Work with the concave grating involved exposures of from 2 to ro hours for the gases. As a rule, the cadmium was exposed before and after each of the others. A neon exposure was added to each plate because of the convenience in using the neon wave lengths for determining the order of interference or size of etalon. ${ }^{14}$

A series of etalons made of invar was used to separate the interferometer plates by distances of $2,3.75,10,15,20,25$, and $40 \mathrm{~mm}$. Most of the wave lengths given in the tables are the mean values of 6 to Io or more comparisons with the primary standard and the majority of these values are derived from the use of 25 or $40 \mathrm{~mm}$ etalons. The relative values obtained from the small etalons (2 and $3.75 \mathrm{~mm}$ ) were used with those derived from the larger ones (25 and $40 \mathrm{~mm}$ ) to find the corrections which were applied to the final wave lengths to eliminate differences in apparent penetration of the interferometer films as described elsewhere. ${ }^{15}$ The interferometer plates used with the prism spectrograph were of fused quartz, plated with nickel, and for the work with the grating glass plates coated with thin copper films were used. These interference etalons were mounted in the chamber for temperature 
control used in the work of this Bureau on the index of refraction of air and described previously. ${ }^{16}$

The long exposures mentioned above required careful temperature control of the interferometer so as to guard against changes either in the dimensions of the interfcrometer or in the refractive index of the air between the plates. For about half of the exposures the interferometer was maintained at $15^{\circ} \mathrm{C}$ and for the remainder it was held closer to room temperature $\left(20\right.$ to $\left.22^{\circ} \mathrm{C}\right)$. The small corrections necessary for deviations of air pressure and temperature from normal conditions were made from tables prepared for this purpose. ${ }^{17}$

\section{RESULTS}

Wave lengths of the stronger lines in the spectra of argon, krypton, and xenon are given in Tables I, 3, and 5, respectively, in which the values for 50 argon lines, 18 krypton, and 12 xenon are presented. Most of the values are thought to be correct within one or two thousandths of an angstrom. Values obtained by other observers, using the same method and based on the international primary standard, are added for purposes of comparison. All the wave lengths are therefore expressed in international angstrom units and represent the lengths of waves in air at a temperature of $15^{\circ} \mathrm{C}$ and pressure of $760 \mathrm{~mm}$ mercury.

TABLE 1.-Wave Lengths in the Argon Spectrum

\begin{tabular}{|c|c|c|c|c|c|}
\hline Intensity & $\begin{array}{l}\text { Bureaus of } \\
\text { Standards }\end{array}$ & Meissner $a$ & Intensity & $\begin{array}{l}\text { Bureaus of } \\
\text { Standards }\end{array}$ & Meissner a \\
\hline ( & $\begin{array}{c}\lambda \\
3948.980 \\
4044.419 \\
4158.591 \\
4164.180 \\
4181.884\end{array}$ & 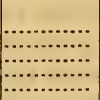 & 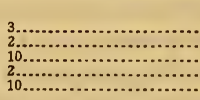 & $\begin{array}{l}\lambda \\
6871.290 \\
6937.666 \\
6965.429 \\
7030.250 \\
7067.217\end{array}$ & (1) \\
\hline 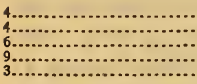 & $\begin{array}{l}4190.714 \\
4191.027 \\
4198.316 \\
4200.676 \\
4251.184\end{array}$ & 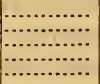 & $\begin{array}{l}5 \\
2 \ldots \ldots \ldots \ldots \\
2 \ldots \ldots \ldots \ldots \\
2 \ldots \ldots \ldots \ldots \\
2 \ldots \ldots \ldots \ldots\end{array}$ & $\begin{array}{l}7147.042 \\
7206.986 \\
7272.935 \\
7353.316 \\
7372.119\end{array}$ & 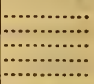 \\
\hline 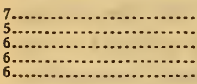 & $\begin{array}{l}4259.362 \\
4266,286 \\
4272.169 \\
4300.101 \\
4333.561\end{array}$ & 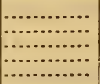 & $\begin{array}{l}9 \\
8 \ldots \ldots \\
20 \ldots \ldots\end{array}$ & $\begin{array}{l}7383.979 \\
7503.867 \\
7514.651 \\
7635.106 \\
7723.758\end{array}$ & $\begin{array}{l}978 \\
868 \\
648 \\
107 \\
760\end{array}$ \\
\hline 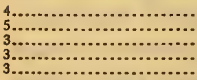 & $\begin{array}{l}4345.168 \\
4510.733 \\
4522.325 \\
4596.096 \\
4628.445\end{array}$ & 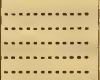 & $\begin{array}{l}4 \\
8 \\
9\end{array}$ & $\begin{array}{l}7724.210 \\
7928.175 \\
8006.156 \\
8014.784 \\
8103.693\end{array}$ & $\begin{array}{l}210 \\
177 \\
158 \\
786 \\
691\end{array}$ \\
\hline (4). & $\begin{array}{l}4702.317 \\
6032.127 \\
6416.307 \\
6677.282 \\
6752.831\end{array}$ & 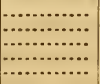 & $\begin{array}{l}9 \\
4 \\
6 \\
3\end{array}$ & $\begin{array}{l}8115.307 \\
8264.522 \\
8408.210 \\
8424.646 \\
8521.442\end{array}$ & $\begin{array}{l}310 \\
525 \\
216 \\
650\end{array}$ \\
\hline
\end{tabular}


Tables 2 and 4 show some of the frequency differences (differences in waves per centimeter in vacuum) which exist among wave lengths of argon and krypton. The constancy of these frequency differences is of interest in view of the high degree of precision which the wave-length measurements are believed to possess. Measurements on the refractive index of air ${ }^{18}$ which were made at this Bureau were used in computing the frequencies in vacuum from the wave lengths in air.

Regularities in the spectrum of argon were first detected by Rydberg, ${ }^{19}$ who listed 23 groups of lines having frequency differences which were repeated from group to group. Additional groups of the same type were pointed out by Paulson. ${ }^{20}$ Then Meissner ${ }^{21}$ determined some of the longer wave lengths by direct comparison with the cadmium standard and found that the frequency differences among the quadruplets were constant within the limits of probable error in the wave-length measurements. Twenty-eight of the argon lines in Table I belong to quadruplets of this type. Table 2 gives the quadruplets in which two or more of the lines in Table $\mathrm{r}$ are present.

Wave lengths given to two decimal places are taken from the measurements of Kayser ${ }^{22}$ and are converted to the international scale. The line 8667.97 was obtained from diffractiongrating spectra made by this Bureau not yet published. The three decimal-place values are found in Table $x$, except those contained in parenthesis, which are predicted from the others by means of frequency differences in parenthesis and assuming that each of the 12 groups of lines is really a complete quadruplet. It is evident that the frequency differences between lines measured by the interferometer are constant within one part in three or four millions which is the same order of accuracy as the wavelength measurements. This may be regarded as another verification of the exactness of the Combination Principle of Ritz. On the other hand, if these frequency differences are really constant, it follows from Table 2 that the measurements determining the relative values of wave lengths involved in these combinations can not be in error by more than one or two thousandths

${ }_{18}$ B. S. Bull., 14, p. 712; 1918.

${ }^{19}$ Astroph. J., 6, p. 338; 1897.

20 Physik. Z., 15, p. 831 ; r914.
21 Physik. Z., 17, p. 549; x916.

$\approx$ Astroph. J., 4, p. $1 ; 8896$. 
of an angstrom. The following frequency relations may be considered to hold throughout each group of four lines:

$$
\begin{aligned}
& \nu_{2}=\nu_{1}+606.837 \\
& \nu_{3}=\nu_{2}+803.075=\nu_{1}+1409.912 \\
& \nu_{1}=\nu_{3}+846.162=\nu_{2}+1649.237=\nu_{1}+2256.074
\end{aligned}
$$

TABLE 2.-Frequency Differences in the Argon Spectrum

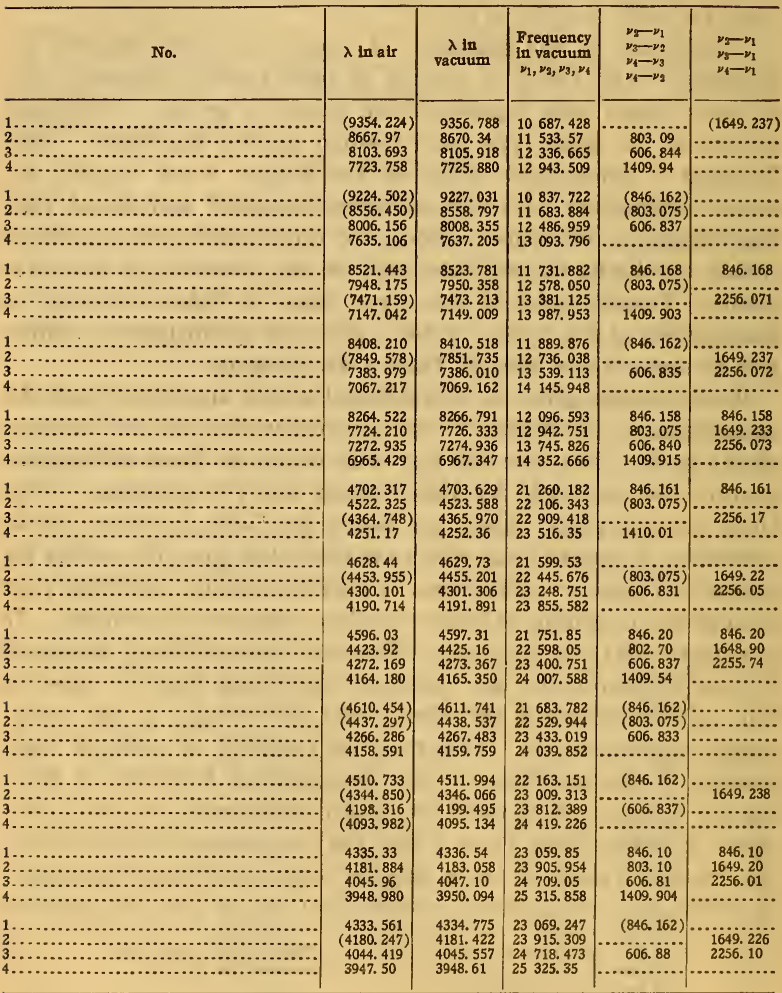


TABLE 3.-Wave Lengths in the Krypton Spectrum

\begin{tabular}{|c|c|c|c|c|c|}
\hline Intensity & $\begin{array}{l}\text { Bureau of } \\
\text { Standarda }\end{array}$ & $\begin{array}{c}\text { Buisson } \\
\text { and Fabry } a\end{array}$ & Intensity & $\begin{array}{l}\text { Bureau of } \\
\text { Standards }\end{array}$ & $\begin{array}{c}\text { Buisson } \\
\text { and Fabry } a\end{array}$ \\
\hline 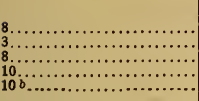 & $\begin{array}{c}\lambda \\
4273.9696 \\
4282.967 \\
4318.552 \\
4319.580 \\
4355.478\end{array}$ & 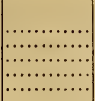 & 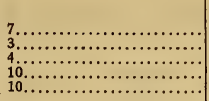 & $\begin{array}{l}\lambda \\
4502.354 \\
4807.065 \\
5562.224 \\
5570.2872 \\
5870.9137\end{array}$ & 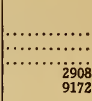 \\
\hline 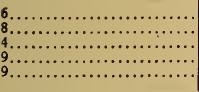 & $\begin{array}{l}4362.6422 \\
4376.122 \\
4399.969 \\
4453.9174 \\
4463.690\end{array}$ & 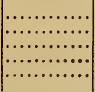 & 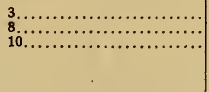 & $\begin{array}{l}6456.290 \\
7587.414 \\
7601.544\end{array}$ & $\begin{array}{l}\ldots \ldots \ldots \cdots \\
\cdots \cdots \cdots \cdots \\
\cdots \cdots \cdots\end{array}$ \\
\hline
\end{tabular}

a Comptes Rendus, 156, p. $945 ;$ i913.

$b$ Second spectrum.

TABLE 4.-Frequency Differences in the Krypton Spectrum

\begin{tabular}{|c|c|c|c|c|}
\hline No. & $\lambda$ in air & $\underset{\text { vacuum }}{\lambda \text { in }}$ & $\begin{array}{c}\text { Frequency } \\
\text { in vacuum } \\
\nu_{1}, \nu_{2}\end{array}$ & $\nu_{2}-\nu_{1}$ \\
\hline 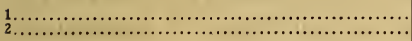 & $\begin{array}{l}8776.73 \\
8104.33\end{array}$ & $\begin{array}{l}8779.14 \\
8106.55\end{array}$ & $\begin{array}{ll}11 & 390.64 \\
12 & 335.70\end{array}$ & 945.06 \\
\hline 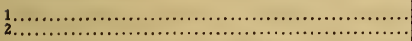 & $\begin{array}{l}8298.07 \\
7694.53\end{array}$ & $\begin{array}{l}8300.35 \\
7696.64\end{array}$ & $\begin{array}{l}12047.68 \\
12992.68\end{array}$ & 945.00 \\
\hline 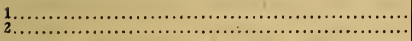 & $\begin{array}{l}8190.02 \\
7601.544\end{array}$ & $\begin{array}{l}8192.27 \\
7603.633\end{array}$ & $\begin{array}{ll}12 & 206.62 \\
13 & 151.608\end{array}$ & 944.98 \\
\hline 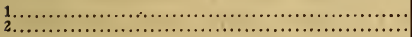 & $\begin{array}{l}5879.85 \\
5570.2872\end{array}$ & $\begin{array}{l}5881.48 \\
5571.8296\end{array}$ & $\begin{array}{l}17002.52 \\
17947.426\end{array}$ & 944.91 \\
\hline$\frac{1}{2} \ldots \ldots \cdots$ & $\begin{array}{l}5870.9137 \\
5562.224\end{array}$ & $\begin{array}{l}5872.5370 \\
5563.765\end{array}$ & $\begin{array}{l}17028.415 \\
17973.441\end{array}$ & 945.026 \\
\hline 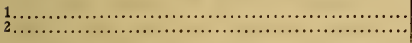 & $\begin{array}{l}4502.354 \\
4318.552\end{array}$ & $\begin{array}{l}4503.613 \\
4319.765\end{array}$ & $\begin{array}{ll}22 & 204.396 \\
23 & 149.426\end{array}$ & 945.030 \\
\hline 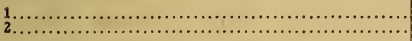 & $\begin{array}{l}4463.690 \\
4282.967\end{array}$ & $\begin{array}{l}4464.938 \\
4284.168\end{array}$ & $\begin{array}{ll}22 & 396.725 \\
23 & 341.755\end{array}$ & 945.030 \\
\hline 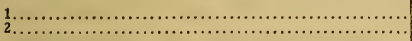 & $\begin{array}{l}4453.9174 \\
4273.9696\end{array}$ & $\begin{array}{l}4455.163 \\
4275.168\end{array}$ & $\begin{array}{l}22445.866 \\
23 \\
390.893\end{array}$ & 945.027 \\
\hline
\end{tabular}

Pairs of lines in the spectrum of krypton having the same frequency difference were first discovered by Paulson. ${ }^{23}$ Similar pairs among the longer wave lengths were found by Merrill. ${ }^{24}$ Some of these are reproduced in Table 4 in which the last four pairs are completely represented by the wave lengths in Table 3. The constancy of these frequency differences is really remarkable since no value differs from the mean $(945.028)$ by more than one part in about Io millions of the wave number.

Pairs of lines suspected of having constant frequency differences have had attention called to them by Paulson, ${ }^{25}$ but all of these associate rather faint lines with the stronger ones of Table 5 and these data are therefore not complete enough to

${ }^{23}$ Ann. d. Phys., 45, p. 428; 1914. ${ }^{25}$ Astroph. J., 40, p. 298; 1914.

34 B. S. Scientific Papers, 15, p. 251 ; 1919. 
test the constancy of frequency differences in this spectrum. It is hoped to extend the wave-length measurements to fainter lines as soon as more spectrum tubes of xenon gas can be obtained.

TABLE 5.-Wave Lengths in the Xenon Spectrum

\begin{tabular}{|c|c|c|c|c|c|}
\hline Intensity & $\begin{array}{c}\text { Bureau } \\
\text { of } \\
\text { Standards }\end{array}$ & Intensity & $\begin{array}{c}\text { Bureau } \\
\text { of } \\
\text { Standards }\end{array}$ & Intensity & $\begin{array}{c}\text { Bureau } \\
\text { of } \\
\text { Standarda }\end{array}$ \\
\hline 8.... & $\underset{4500.978}{\lambda}$ & $9 \ldots$. & $\begin{array}{c}\lambda \\
4624.275\end{array}$ & $7 \ldots \ldots$ & $\underset{4807.019}{\lambda}$ \\
\hline $6 \ldots \ldots$ & 4524.680 & $10 \ldots$ & 4671.225 & $4 \ldots \ldots \ldots$ & 4829.705 \\
\hline $4 \ldots \ldots$ & 4582.746 & $6 \ldots \ldots \ldots$ & 4697.020 & 10 a...... & 4844.333 \\
\hline $10 a \ldots .$. & 4603.028 & $8 \ldots \ldots$ & 4734.154 & $5 \ldots \ldots \ldots$ & 4923.246 \\
\hline
\end{tabular}

\section{SUMMARY}

The spectra of the inert gases contain strong lines which represent wave lengths possessing a high degree of homogeneity and reproducibility and are therefore suitable for use as standards of wave length. This paper gives the values of 50 wave lengths in the spectrum of argon, 18 of krypton, and 12 of xenon, all of which have been compared with the international primary standard by means of interferometers. The wave lengths are considered to be correct to $0.001 \mathrm{~A}$ in most cases. The elegance and refinement of the interferometer methods for wave-length comparisons are evidenced by the close agreement between values obtained by different observers, and also by the constant frequency differences of many of the lines belonging to combination series. There are only a few cases where independent observers differ by $0.004 \mathrm{~A}$ or more. From wave-length measurements in argon and krypton frequency differences are obtained which are constant within the probable error of the measurements. This further confirms the exactness of the Combination Principle of Ritz. If these frequency differences are considered as true constants, they certify to the accuracy in relative value of the wave lengths involved. More work of this kind on the part of different observers is very much to be desired so that an extended system of accurate secondary standards will ultimately be produced.

WASHINGTON, May 9, I92I. 